\title{
CARNE MACIA COM OS OSSOS AFIADOS: EPISTEMICÍDIO E MULTILINGUÍSMO EM HIBISCO ROXO, DE CHIMAMANDA ADICHIE
}

\author{
SOFT MEAT WITH SHARP BONES: \\ EPISTEMICIDE AND MULTILINGUALISM IN PURPLE HIBISCUS, \\ BY CHIMAMANDA ADICHIE
}

\section{Fernanda de Oliveira Cerqueira* Rômulo Gonçalves Bittencourt ${ }^{\star *}$}

\begin{abstract}
RESUMO
Este trabalho propõe-se a analisar a obra Hibisco Roxo (2011), de Chimamanda Ngozie Adichie - romance permeado por tensões de raça e de gênero, provocadas pelo imperialismo inglês na Nigéria, sob o prisma dos conflitos políticos e socioculturais ambientados no capitalismo. Partindo do conceito de epistemicídio, proposto por Carneiro (2005), com base em Foucault (1979) e Sousa Santos (1995), verificamos, nas práticas multilíngues, os valores atribuídos às línguas originais, com destaque para o Igbo, e à língua do colonizador na implementação e na vigência dos empreendimentos colonialista e imperialista. Considerando que a escrita de Adichie (2011) permite outra leitura possível dos conflitos vivenciados pela sociedade nigeriana atual, há, no âmbito linguístico, evidências de que a língua inglesa, elemento constitutivo da colonização, representaria, a partir das práticas linguísticas das personagens, uma vinculação ao processo imperialista - subjacente à ação do capitalismo sob o recente término da colonização. Já as práticas linguísticas do Igbo representariam estratégia de resistência, através do resgate às tradições ancestrais, como via de rasurar o epistemicídio, tensionando as estratégias de apagamento da cultura Igbo. Há, assim, um jogo de poder no qual a língua exerce um papel importante na marcação simbólica de processos de dominação/assimilação e/ou oposição/ resistência sociocultural, ambos atravessados pela religião.
\end{abstract}

Palavras-chave: epistemicídio; multilinguísmo; Hibisco Roxo; colonização nigeriana; imperialismo.

\section{ABSTRACT}

This paper aims to analyze the work Hibisco Roxo (2011), by Chimamanda Ngozie Adichie - a novel permeated by race and gender tensions, caused by English imperialism in Nigeria, under the prism of political and socio-cultural conflicts set in capitalism. Starting from the concept of epistemicide, proposed by Carneiro (2005), based on Foucault (1979) and Sousa Santos (1995), we verify, in multilingual practices, the values attributed to the original languages, with emphasis on Igbo in this work, and the language of colonizer in the implementation and term of colonialist and imperialist undertakings. Considering that Adichie's writing (2011) allows another possible reading of the conflicts experienced by the current Nigerian society, there is, in the linguistic scope, evidence that the English language, a constituent element of colonization, would represent, based on the linguistic practices of the characters, a linkage to the imperialist process - underlying the action of capitalism under the recent end of colonization. Igbo's linguistic practices, on the other hand, would represent a strategy of resistance, through the rescue of ancestral traditions, as a way of erasing the epistemicide, tensioning the policies for erasing the Igbo culture. Thus, there is a power game in which the language plays an important role in the symbolic marking of processes of domination/assimilation and/ or opposition/socio-cultural resistance, both crossed by religion.

Keywords: epistemicide; multilingualism; Purple Hibiscus; nigerian colonization; imperialism.

\section{INTRODUÇÃO}

A linguagem humana sempre despertou muito interesse de diversos setores das ciências, culminando, inclusive, em diferentes perspectivas de compreensão desse fenômeno que ora tende a ser tratado como formal, ora como funcional/social. Em vista disso, adotamos no presente trabalho a concepção de língua como prática social, atravessando, em muitos aspectos a perspectiva funcional, por conta de seu perfil indisciplinar, fruto da sua atuação "[...] como instrumento de construção do conhecimento e da vida social" (MOITA LOPES, 2009, p. 18).

Tal abordagem, por seu caráter indisciplinar (MOITA LOPES, 2006), nos possibilitou flertar com outros campos do saber, como História, Literatura, além da Linguística Geral e, em alguma medida, da Linguística Aplicada,

\footnotetext{
* Doutora em Língua e Cultura, pelo Programa de Pós-Graduação em Língua e Cultura da Universidade Federal da Bahia (UFBA), Salvador, BA, Brasil.f.cerqueira@hotmail.com

Orcid: https://orcid.org/0000-0002-2515-9371

** Graduado em Direito pela Universidade Federal da Bahia (UFBA), Salvador, BA, Brasil. romulo.g.bittencourt@gmail.com

Orcid: https://orcid.org/0000-0003-1325-4950
} 
para compreensão de práticas multilíngues e epistêmicas, na obra "Purple Hibiscus" ${ }^{1}$, da autora nigeriana, Chimamanda Ngozie Adichie, cuja primeira impressão foi em 2003. O referido romance é marcado por tensões raciais decorrentes do impacto de décadas de colonização inglesa, a qual culminou em uma série de embates epistemológicos, regulados pelo racismo ${ }^{2}$, pelo capitalismo e pelo cristianismo. Ademais, o sexismo também é um sistema de opressão denunciado nessa narrativa.

Segundo o filósofo camaronês Mbembe (2018, p. 38), a "ocupação colonial" precisa ser tratada como demarcação e afirmação de controle físico e geográfico de povos dominados, haja vista que se inscrevem sobre o território em questão novas normas de relações sociais e espaciais. Consequentemente, o projeto colonial impõe fronteiras, zonas, regimes, hierarquias, extração de recursos e categorização de pessoas subsidiando o imaginário, por meio do qual são instituídos direitos diferentes às categorias estabelecidas, correspondendo à hierarquia social oriunda da colonização e de seus desdobramentos em termos de estratificações raciais, econômicas, de gênero e de sexualidade.

Portanto, ainda que o término formal da colonização inglesa tenha findado, seus impactos culturais subsidiaram as estruturas sociais da Nigéria, ao passo que, diante da narrativa apresentada por Adichie (2011), o imaginário de parte da população nigeriana tende a ser orientado, em muitos eventos, por perspectivas ocidentais e racializantes, legados do empreendimento colonial, reforçados com o imperialismo. Cabe destacar que a discussão aqui proposta se centra na versão traduzida da obra, de modo que

[n]a tradução do romance para o Português do Brasil, intitulada Hibisco Roxo, a tradutora optou por manter os trechos em igbo e o destaque em itálico do original em inglês. Com isso, manteve as marcas de etnicidade na tradução, e realizou o que Antoine Berman (2013), em A Tradução e a Letra ou O Albergue do Longínquo, denomina de uma tradução ética, ou seja, fiel à letra da obra (MÜLLER, 2016, p. 15)

De acordo Müller (2016), o trabalho de Júlia Romeu se configura como uma tradução ética, uma vez que além de apresentar uma breve biografia de Chimamanda Adichie - com fito de defender um paradigma literário acerca de África e da Nigéria em que não se perpetuem estereotipias ocidentais - a tradutora apresenta um breve resumo dos personagens nucleares a fim de ultrapassar as recorrentes representações do continente africano marcadas por cenários de miséria, guerra e doenças. Ademais, foi apresentado um mini glossário com tradução aproximada de palavras da língua Igbo para português brasileiro.

A Nigéria, uma república constitucional federal, localizada no Golfo da Guiné, é atualmente o país mais populoso de África, possui trinta e seis estados, sendo Abuja, uma cidade planejada, tal qual Brasília, a sua capital. É um dos maiores exportadores de petróleo e, segundo Vissentini (2011), contempla cerca de duzentos e cinquenta grupos étnicos, sendo a maior parte dessas umиnna ${ }^{3}$, pertencente a quatro grandes grupos, a saber, Hauçás, Fulani, Iorubás e Igbos, como também retratado por Gonçalves (2006), na obra literária Um defeito de cor. Ainda que a Nigéria seja, por excelência, um país multilíngue, não por acaso, as línguas mais faladas no país são Iorubá, Hauçá, Fulani, Igbos e inglês, sua língua oficial, como traço preponderante da colonização britânica, na língua e pela língua (MUFWENE, 2016).

Logo, a representação das personagens remonta a identidades e mediações culturais nigerianas em que se verifica a dualidade linguística, do Igbo para o inglês e vice-versa, materializando as relações construídas na língua e pela língua, remontando à urgente reflexão sobre as aproximações e distanciamentos entre políticas linguísticas e políticas na Linguística (MUNIZ, 2009). Desse modo, o presente trabalho visa analisar a obra Hibisco Roxo, a partir do conceito de epistemicídio, proposto por Carneiro (2005), com base em Foucault (1979) e Sousa Santos (1995), a fim de verificar, nas práticas multilíngues, os valores atribuídos às línguas originais e à língua do colonizador na implementação e na vigência dos empreendimentos colonialista e imperialista.

\section{OS EFEITOS DA COLONIZAÇÃO}

As aproximações entre História e Literatura são inevitáveis. Afinal, a narrativa, enquanto recurso revelador de uma explicação proposta, torna-se compreensível por meio da ordenação de fatos, ações e experiências de indivíduos

1. O nome da obra é apresentado nesse momento em inglês para registrar a primeira versão da publicação original, em 2003. Porém, a seguir a obra será tratada como Hibisco Roxo, já que o trabalho se debruça sobre a versão traduzida para o português brasileiro, de 2011.

2. Processo de discriminação racial que extrapola a esfera do preconceito individual, marcando a coletividade por se caracterizar como pilar social, com base em ações nos campos da ideologia, da política, do direito e da economia (ALMEIDA, 2018).

3. Termo em Igbo utilizado na obra literária Hibisco Roxo para fazer referência à subgrupo étnico similar à irmandade, confraria ou clã. 
(GALLIE, 2016), se constitui como elemento indissociável do fazer historiográfico e literário. Não obstante, há, ainda hoje, um debate em torno da natureza da produção histórica ${ }^{4}$. Portanto, a questão aqui posta em discussão diz respeito ao grau de contribuição instrumental, metodológica e de conteúdo que cada instância teórica pode oferecer a outra.

Partindo desse breve pensamento, faz-se necessário refletir sobre como as representações literárias acerca da língua - em seu processo identitário - podem ser objeto de ponderações no âmbito da História. Para tanto, o livro Hibisco Roxo, mostrou-se um excelente corpus, na medida em que, no curso do enredo engendrado por Adichie (2011), tensões político-culturais historicizadas são manifestadas nas línguas e pelas línguas, mais precisamente, o Igbo e o inglês.

Dentro desta perspectiva, se procederá uma crítica da referida obra como fonte histórica, mobilizando a perspectiva de superação documento-monumento proposta por Le Goff (2003 [1988]). Em outras palavras, o texto literário objeto de discussão será compreendido incorporando questões extratextuais, os quais ajudam a identificar as relações de poder em disputa tanto na elaboração da narrativa quanto nas leituras que dela se fazem. Nesse sentido, o modo pelo qual os personagens do livro Hibisco Roxo são apresentados por Adichie (2011) nos permite enveredar no processo histórico de conformação da Nigéria atual. Afinal, "toda a história é bem contemporânea, na medida em que o passado é apreendido no presente e responde, portanto, aos seus interesses, o que não é só inevitável, como legítimo" (LE GOFF, 2003 [1988], p.41).

Nessa empreitada, Adichie (2011) contribui para estreitamento das relações entre Literatura e História, servindo como mote para discussões de como as representações literárias retomam, revelam e enaltecem questões históricas ainda pouco exploradas no âmbito historiográfico, a exemplo do uso da língua como prática social constitutiva dos processos colonialista e imperialista

Logo, a representação literária produzida com base nas línguas faladas como uma das referências culturais da Nigéria, a partir de Hibisco Roxo, seria, pois, objeto de estudo, dentro de uma dimensão da História Cultural. Aliás, o uso da obra em destaque como fonte histórica em conjunto com a historiografia, bem como as próprias contribuições da área da Linguística, servirá de fio condutor para o debate sobre o complexo jogo de relações de poder em disputa frente à tensão em que as personagens de Adichie estão imersas no período pós-colonização inglesa na Nigéria.

Outrossim, não é possível dissociar a obra de Adichie do contexto histórico em que foi produzida, tampouco afora do lugar de fala da autora (RIBEIRO, 2017), cujo lócus social é de mulher negra cisgênero, heterossexual, de classe média, acadêmica e nigeriana. Afinal, como anuncia Ginzburg (1989), o testemunho também pressupõe a análise daquilo que escapa, é dizer, os atos falhos que denunciam a especificidade, a qual se dá, estrategicamente, pelo método indiciário, capaz de discernir o deslize inconsciente e, também, a omissão deliberada.

Em certa medida, apesar do olhar de Adichie (2011) constituir a espinha dorsal de seu texto, existem elementos que podem ser extraídos para além do ponto de vista da narradora. Nesse viés, Farra (1978) destaca que a ótica expressa na narrativa é apenas um referencial para o leitor, o qual certamente irá ressignificar as questões sugestionadas. Não haveria, sob esse prisma, unicidade na intepretação textual, considerando a natureza viva, instável e aberta do texto (BORGES, 2020), isto é, como um evento cultural (BARREIROS, 2018), produtor de sentidos para além da sua materialidade, mediante sua circulação, transmissão e recepção (MCKENZIE, 2018 [1986]).

De fato, o conjunto das obras de Adichie demonstram sua intenção de apresentar outras perspectivas sobre a Nigéria, notadamente pela ênfase na superação de estereótipos forjados pelo imaginário do ocidente (MBEMBE, 2003, 2014, 2015; TEOTÔNIO, 2013), por conseguinte, a produção de outras histórias com visões locais parece ser a tônica das obras de Adichie. A exemplo disso, no vídeo ou no livro O perigo de uma única bistória ${ }^{5}$, ela denuncia o perfil exótico e racializante, além da fetichização da pobreza, atribuídos aos povos africanos. Em vista disso, a autora frisa a necessidade da circulação e do reconhecimento de narrativas diversas, pluralizando a escrita da história, mediante as quais sejam evidenciadas as problemáticas reais e contemporâneas das populações africanas, em sua diversidade, que não podem ser unificadas. Por essa razão, provavelmente, a construção de personagens em Hibisco Roxo é tão

4. O debate sobre a natureza do procedimento de narrar o passado envolve a reflexão sobre o status cientificidade da História. De Leopold Van Ranke a François Dosse, passando por Robin George Collingwood, Paul Veyne e Roger Chartier, até o debate entre Carlo Ginzburg e Hayden White, a teoria da história ainda se encontra envolvida pela necessidade de compreensão da natureza mesma do conhecimento histórico, na qual a narrativa histórica é o seu produto mais imediato.

5. Vídeo extraído do site do Youtube, disponível em https://www.youtube.com/watch?v=wQk17RPuhW8, acessado em 24 de nov. de 2018. Também disponível em versão livro físico e e-book, traduzido para o português, pela Companhia das Letras, em 2019. 
diversificada não só em relação a categorias socioeconômicas (pobres, integrantes da elite e classe média nigeriana), mas, sobretudo, na relação identitária com o processo histórico de colonização inglesa.

Embora em Hibisco Roxo a discussão se concentre nas repercussões do imperialismo britânico na vida Kambili, parece importante ressaltar que o processo histórico de formação do que hoje se entende por nação nigeriana perpassa, em um primeiro momento, pela experiência colonial e, em seguida, pela disputa imperialista das nações europeias em África.

A diversidade de grupos autóctones (Hauçá, Igbo, Fulani, Iorubá, dentre outros) da região envolta pelo Golfo da Guiné atravessa a própria conformação do que hoje se entende por Nigéria, além de tonalizar o multilinguísmo da região, problematizada em Hibisco Roxo pelo uso da língua Igbo. Durante o século XV, a mercantilização de sujeitos escravizados no transatlântico - em especial da região de Lagos (REIS, 2008) - repercutiu intensamente na política e na economia da Nigéria, cujo desdobramento se deu ao longo do século XIX, com ingresso de missionários cristãos fundadores de escolas primárias (BOAHEN, 2010), abrindo espaço para atuação do capitalismo britânico com exploração de matérias-primas locais. Aliás, em Hibisco Roxo, esse contexto histórico é representado através da formação do personagem Eugene (Papa), conforme será adiante demonstrado.

Cabe destacar ainda que, após muitos anos submetida ao colonialismo britânico, a Nigéria deflagrou sua independência em 1960, de modo que há, consequentemente, remanescentes desse vasto processo de exploração, os quais constituem, conforme aspectos apresentados na obra, elementos estruturantes dessa sociedade, a saber, racismo, capitalismo e sexismo. Decerto, não só frentes socioeconômicas, bem como identitárias, constroem-se sob forte tensão entre as culturas tradicionais e a cultura ocidental, eurocêntrica cristã, revelando evidências de uma África Insubmissa, cuja insubordinação confronta as pretensões cristãs de hegemonia, como argumenta Mbembe (2003):

[p]or um lado, e além do problema da definição de Deus dos cristãos e da 'adesão' dos vencidos à sua Igreja, perfilava-se uma questão de poder e, de certo modo, o futuro de um regime de supremacia estava em jogo. Para se esgueirar deste regime de supremacia ou, pelo menos, para atenuar a sua austeridade, o [africano] não se coibiu de recorrer à indisciplina e à indocilidade que sua inscrição subordinada no domínio colonial não tinha conseguido [fazer] eliminar. Por outro lado, a sua 'conversão' foi tudo menos neutra ou gratuita. De qualquer modo - e correndo o risco de lesar certa teologia romântica - fundamentalmente, ela não é fruto do Espírito Santo. O facto de que as sociedades [africanas] se terem deixado, por assim dizer, 'aliciar' e depois 'capturar' por determinadas regiões - e não pela totalidade - do cristianismo, significa precisamente que sua 'conversão' foi seletiva (MBEMBE, 2003, p. 15-16).

É nesse cenário que se inscreve o enredo de Hibisco Roxo, no qual Kambili, protagonista da trama, garota de quinze anos, narra sua trajetória familiar, atravessada por tensões de gênero, de raça, de classe e de religião. Assim, a narrativa tecida por Kambili gira em torno, especialmente, de sua convivência com: a. com seu pai, Eugene (Papa) - um empresário rico, católico fundamentalista, influente e violento no âmbito familiar, que repugna a cultura e as heranças ancestrais; b. com a mãe, Beatrice (Mama) - uma mulher silenciada e submissa diante do ciclo de relacionamento abusivo; c. com seu o irmão mais velho, Chukwuka (Jaja), de 17 anos, o qual vivencia a descoberta da própria identidade, representada pelos hibiscos roxos, evento que o motiva a questionar a tirania do pai; e d. com sua tia paterna, Ifeoma, professora acadêmica, viúva, experiente e determinada, cuja criação dos três filhos (Amaka, Obiora e Chima) visa o fomento de senso crítico e independência.

Ademais, a trama de Hibisco Roxo possui como pano de fundo os desdobramentos do longo processo de independência da Nigéria em relação ao Reino Unido, conforme se percebe pelo itinerário dos referidos personagens diante das tensões políticas do país, tais como o golpe militar e a censura instaurada, em decorrência desse evento.

É preciso destacar, como mencionado em diferentes momentos da narrativa do livro, que as repercussões do colonialismo e do imperialismo no referido país se manifestam também pelo viés da linguagem, a qual é instrumentalizada tanto como via de acesso a espaços de prestígio, quanto como marca de filiação ideológica dos personagens.

\section{DINÂMICA MULTILÍNGUE E SEUS EFEITOS DE SENTIDO}

\subsection{0 breve preâmbulo etnolinguístico}

De acordo com Lemos (2018), é da relação entre língua e cultura que há possibilidade de transmissão de modos de vida, de ser, de estar e de pensar. Sob esse viés, a autora aponta que o multilinguísmo reflete um cenário em que várias línguas coabitam ou coexistem, ainda que indivíduos monolíngues ignorem a língua um do outro. Por 
outro lado, o plurilinguismo se configuraria em contextos cujos indivíduos estão aptos a exprimir diferentes níveis de habilidades comunicativas nas línguas em questão.

Para Bassani (2015), o multilinguísmo tende a se manifestar de duas maneiras, como fenômeno territorial. A primeira, quando, em um país, apenas a língua nacional é reconhecida oficialmente, embora haja inúmeras pessoas bilíngues ou multilíngues, fruto de imigrações em que se preserva a língua materna. E o segundo, no qual há, em um país, apenas uma língua nacional reconhecida oficialmente, ainda que haja inúmeras comunidades autóctones, nas quais são mantidas as línguas maternas, amplamente utilizadas antes da colonização.

É justamente sobre este último a centralidade deste trabalho ${ }^{6}$ : discutir elementos socioculturais norteadores dos usos da língua materna (Igbo) e aquela fruto do colonialismo e do imperialismo europeu (inglês), no sudeste nigeriano, por meio da representação identitária das personagens da obra Hibisco Roxo. Além disso, diante da narrativa apresentada por Adichie (2011), há, aparentemente, um cenário de multilinguísmo e não de plurilinguismo, nos termos aqui apresentados. Ao menos, nas regiões do sudeste do país.

No entanto, é importante reiterar, como já dito por Canagarajah e Liyanage (2012), que embora o multilinguísmo seja comumente considerado como um fenômeno da pós-modernidade, a constituição das organizações sociais de um povo não se iniciaram com a colonização. Nesse sentido, "[...] uma compreensão de práticas linguísticas pré-coloniais nos ajudarão a apreciar práticas comunicativas em tempos contemporâneos" (CANAGARAJAH; LIYANAGE, 2012, p. 49). Portanto, a compreensão de práticas linguísticas multilíngues apresenta forte colaboração para valorização dos sujeitos falantes das línguas originais, podendo minimizar os impactos de seu apagamento.

Para compreensão desse panorama de apagamento cultural dos povos originários, assim como seus impactos na linguagem, devido ao colonialismo e ao imperialismo, respectivamente, acionamos aqui o conceito de epistemicídio. Assim, com base em Foucault (1979) e em Sousa Santos (1995), Carneiro (2005, p. 2) propõe a revisão do fenômeno do epistemicídio, de modo que

[...] da dupla articulação do dispositivo de racialidade ao biopoder emerge um mecanismo específico que compartilha da natureza dessas duas tecnologias de poder: o epistemicídio, que coloca em questão o lugar da educação na reprodução de poderes, saberes, subjetividades e 'cídios' que o dispositivo de racialidade/biopoder produz (CARNEIRO, 2005, p. 2).

Dito de outro modo, o epistemicídio atua como operador a partir do qual se estabelecem estratégias de inferiorização da pessoa negra, culminando no rebaixamento de sua produção intelectual, tanto no âmbito cultural mais amplo, quanto na esfera acadêmica. Diante disso, esse é

[...] um conceito extraído da reflexão de Boaventura Sousa Santos (1995), que integramos ao dispositivo de racialidade/biopoder, como um dos seus operadores por conter em si tanto as características disciplinares do dispositivo de racialidade quanto as de anulação/morte do biopoder. É através desse operador que este dispositivo realiza as estratégias de inferiorização intelectual do negro ou sua anulação enquanto sujeito de conhecimento, ou seja, formas de sequestro, rebaixamento ou assassinato da razão. Ao mesmo tempo, e por outro lado, o faz enquanto consolida a supremacia intelectual da racialidade branca (CARNEIRO, 2005, p. 10).

Em vista disso, o epistemicídio (CARNEIRO, 2005) é crucial para a manutenção da orientação de sistemamundo colonial, assim como do racismo estrutural, uma vez que duas das suas principais frentes de tensionamento são comprometidas, a saber, a representatividade e a mobilização coletiva. Assim, na mesma direção que Carneiro (2005), Mbembe (2016) argumenta que

[e]sse controle [colonial] pressupõe a distribuição da espécie humana em grupos, a subdivisão da população em subgrupos e o estabelecimento de uma cesura biológica entre uns e outros. Isso é o que Foucault rotula com o termo (aparentemente familiar) 'racismo'. Que a 'raça' (ou, na verdade, o 'racismo') tenha um lugar proeminente na racionalidade própria do biopoder é inteiramente justificável. Afinal de contas, mais do que o pensamento de classe (a ideologia que define história como uma luta econômica de classes), a raça foi a sombra sempre presente sobre o pensamento e a prática das políticas do Ocidente, especialmente quando se trata de imaginar a desumanidade de povos estrangeiros - ou dominá-los (MBEMBE, 2016, p. 138).

Por conseguinte, há um jogo de poderes instituído pelo sistema colonial por meio do qual se produz condições para a falácia de que as representações culturais, nas suas mais amplas manifestações, do grupo social dominante, colonizador - europeu - branco - cristão - falante de inglês, gozam de prestígio, enquanto que aquelas produções culturais dos grupos dominados, colonizado - africano - negro - pagão - falante de Igbo, devem ser estigmatizadas. Logo, como já dito por Mbembe (2003), a "conversão seletiva" ao cristianismo remonta

6. Não é nossa intenção advogar em função de que saberes ocidentais devam deliberar acerca do que é ou não é multilinguísmo em África, mas simplesmente de conceituar e delimitar o foco da investigação. 
[...] permanentemente [à]s perspectivas de ganhos e lucros simbólicos e materiais propícios à troca dos idiomas religiosos ancestrais pelos idiomas dos vencedores. Na verdade, desde o início que o [africano] se permite instrumentalizar esta nova modalidade, sendo que quis submetê-la a usos sociais adaptados a contextos, conjunturas e interesses inerentes à sua situação no espaço colonial (MBEMBE, 2003, p. 16).

Nesse sentido, ainda que, em muitas ocasiões, os propósitos de segmentos sociais mais abastados, dessa conjectura, tenham coincidido com interesses dos agentes missionários, houve, segundo o autor camaronês, a deliberada intenção de assimilação cultural e, não por acaso, linguística, desses setores com a cultura ocidental, como via de manutenção em espaços de poder.

Com efeito, de acordo com Ernest-Samuel (2019), o fato de, em 2012, a UNESCO incluir o Igbo como uma língua provavelmente extinta em cerca de cinquenta anos, em acordância com os desdobramentos do projeto colonial britânico na Nigéria, culminou em desinteresse dos jovens dessa nação em falarem Igbo em público, assim como de ler a vasta tradição literária produzida nessa língua (UBIWORO, ONOYOVWI, 2008). Não por acaso,

[...] muitas famílias de elite no país e na diáspora preferem que seus filhos dominem o inglês em vez do Igbo. Por este motivo, muitas escolas privadas não contratam professores Igbos, o que resulta em uma escassez ainda maior destes docentes e de estudantes interessados. É provável que os jovens estudem a língua e a literatura Igbo na escola para serem aprovados nos exames, não por interesse pessoal (ERNEST-SAMUEL, 2019, p. 2).

Esse quadro produz condições de negligência e depreciação não só para língua e literatura Igbo, mas também para as normas e valores culturais tradicionais transmitidos geracionalmente (UBIOWORO; ONOYOVWI, 2008; ODINYE; ODINYE, 2010), ao passo que se faz necessária a valorização dessa produção com fito de tensionar a ação do epistemicídio, conforme apresentada aqui. Logo, quanto maior a valorização das línguas faladas na Nigéria, maiores as chances de superação do apagamento dessas epistemologias, estabelecidos no projeto colonial e reforçados com o imperialismo.

\subsection{Padrões sociolinguísticos como construtos identitários}

Mediante ao exposto, a obra Hibisco Roxo se configura como um movimento político, uma vez que há o intuito, no curso da narrativa, de apresentar a diversidade cultural, haja vista que retrata o país da Nigéria em meio a um conturbado período político de intervenção militar. Desse modo, a partir do olhar inocente de Kambili, é possível ter acesso a uma gama de outros personagens de diferentes estratos socioeconômicos, cada uma com visões de mundo e expectativas sociais próprias. Portanto, é através do contato com essa diversidade sociocultural que se percebe a construção de identidades a partir de questões raciais e culturais na Nigéria contemporânea, tendo em vista que

[...] o sujeito pós-moderno [é] conceptualizado como não tendo uma identidade fixa, essencial ou permanente. A identidade torna-se uma 'celebração móvel': formada e transformada continuamente em relação às formas pelas quais somos representados ou interpelados nos sistemas culturais que nos rodeiam (HALL, 1987). É definida historicamente e não biologicamente (HALL, 1992, p. 12).

Nesse âmbito, o sujeito pós-moderno, o qual emerge em um cenário marcado pelas relações de poder imperialistas e pós-coloniais, assume diferentes marcas identitárias, em diferentes circunstâncias, atravessadas por diferentes filiações ideológicas, ao passo que suas identidades não são "unificadas ao redor de um 'eu' coerente" (HALL, 1992, p. 13), mas em função dos perfis dos grupos com os quais se articula. Ainda que o estágio da modernidade não possa ser estabelecido com base nos mesmos parâmetros, com vistas a não invisibilizar epistemologias contracoloniais, a reflexão proposta por Hall (1992) abre possibilidade para compreensão da relação possível entre a representação das personagens e identidades nigerianas.

As cidades de Enugu, Nsukka e Abba, situadas no eixo sudoeste da Nigéria, região em que habitam povos de etnia Igbo (VISSENTINI, 2011), são cenários recorrentes na trama de Adichie (2011), de modo que as tensões linguísticas, não escapam ao escopo das tensões socioculturais já apresentadas. Assim, no âmbito linguístico, há evidências na obra, em estudo, de que a língua inglesa, elemento constitutivo da colonização, representaria, a partir da fala das personagens, uma vinculação ao processo imperialista - subjacente à ação do capitalismo sob o recente término do empreendimento colonial. Já a língua Igbo representaria estratégia de resistência, por meio do resgate às tradições ancestrais. Há, assim, um jogo de poder em que a língua exerce um papel importante na marcação simbólica de processos de dominação/assimilação e/ou oposição/resistência cultural, ambos atravessados pela religião. A seguir, 
serão apresentados os perfis identitários (HALL, 1992, 2003) dos personagens, bem como seus desdobramentos, uma vez que parece inevitável a discussão em torno dos usos políticos das línguas faladas.

Para Eugene Achike (Papa), pai de Kambili, o uso do Igbo, bem como outros traços culturais, tais como a religião, a música ou mesmo a forma de bater palmas, é visto como atraso civilizatório. É um empresário rico, dono do jornal Standard, fundamentalista religioso e aprisiona a família em um constante ciclo de violência física e simbólica, as quais culminam em vários ciclos adoecimento psíquico na configuração familiar.

\begin{abstract}
- Jaja, você não bebeu conosco, gbo? Não há palavras em sua boca? - perguntou, falando em igbo. Aquilo era um mau sinal. Papa quase nunca falava em igbo e, embora Jaja e eu usássemos a língua com Mama quando estávamos em casa, ele não gostava que o fizéssemos em público, ele nos dizia; precisávamos falar em inglês. A irmã de Papa, tia Ifeoma, disse um dia que Papa era muito colonizado. Disse isso de forma gentil e indulgente, como se não fosse culpa de Papa, como quem fala de alguém que tem um caso grave de malária e por isso grita coisas sem nexo (ADICHIE, 2011, p. 20, grifo nosso).
\end{abstract}

Para Müller (2016), o personagem representa setores da sociedade nigeriana que visam negar sua origem, a fim de uma aproximação extremista com a cultura inglesa, do colonizador - dominador - branco - cristão. Segundo Bonnici (2006), Eugene concebe a religião e a língua inglesa como traços de superioridade da cultura ocidental e transpõe radicalmente esse entendimento à sua família. Afinal, "Papa gostava que o povo de Abba se esforçasse para falar inglês perto dele" (ADICHIE, 2011, p. 67).

Papa ainda falava muito dele [sogro], os olhos cheios de orgulho, (...). Ele abriu os olhos antes da maioria do nosso povo, dizia Papa foi um dos poucos que acolheram os missionários. Vocês sabem a rapidez com que ele aprendeu inglês? Quando se tornou um intérprete, sabem quantas pessoas ajudou a converter? Ora, ele converteu pessoalmente quase toda a população de Abba! Fazia as coisas do jeito certo, do jeito que os brancos fazem, não como nosso povo faz agora! (ADICHIE, 2011, p. 35, grifo nosso).

Essa passagem bem denuncia a mobilização de aspectos linguísticos como ferramenta de contraposição e, sobretudo, de clivagens raciais. Afinal, o enaltecimento da aderência do personagem Papa aos costumes ingleses (em especial pela fluência com a língua inglesa), se amolda a ideia de sucesso na vida em contraposição àqueles que resistem ao capitalismo britânico.

A propósito, em várias passagens do livro, Kambili percebia o esforço cotidiano de seu pai, Eugene, na adesão integral a um modus operandi inglês, incluindo o sotaque britânico. O colonizador era visto por Eugene, sob a ótica de Kambili, como padrão hegemônico ao qual o povo nigeriano deveria aderir.

Com base na discussão estabelecida por Mbembe (2003), em África Insubmissa, é possível que a associação de Eugene com a cultura de prestígio seja um empreendimento consciente no intuito da assegurar sua validação como homem de poder, já que, apesar de negro e nigeriano - marcas de estigma sob o prisma colonialista - é rico, machista, cristão e falante de inglês - marcas de prestígio no advento do capitalismo imperialista. Deste modo, verifica-se uma constante busca pela aproximação com o seu opressor, tal qual apresentado pelo psiquiatra martinicano, Frantz Fanon (2008), no clássico Pele negra, máscaras brancas.

Papa mudou de sotaque quando respondeu, adotando uma pronúncia britânica, como fazia quando falava com o padre Benedict. Ele se mostrou gracioso e ansioso por agradar, como sempre era com os religiosos, principalmente os religiosos brancos (ADICHIE, 2011, p. 52, grifo nosso).

Em contrapartida, o pai de Eugene, PapaNnukwu, homem apegado à religião local, não falava, nem compreendia o inglês. No curso da narrativa, é retratado como um sábio ancião que buscava se manter em sintonia à cultura ancestral, por meio do culto aos antepassados, dentro de uma concepção tradicionalista, segundo sua filha Ifeoma.

Eu já ouvira tudo aquilo antes, sobre o quanto ele [Papa] se esforçara, sobre como as irmãs e os padres da missão haviam lhe ensinado coisas que ele jamais teria aprendido de seu pai adorador de ídolos, meu PapaNnukwu (ADICHIE, 2011, p.53).

A avaliação dos personagens retratados na obra, como representações possíveis de identidades nigerianas, sugere um cenário no qual o fenômeno do epistemicídio atua na desvalorização, com fins de apagamento, de práticas linguísticas, religiosas e culturais do povo Igbo. Todavia, a persistência de PapaNnukwu em não aderir ao sistema imperialista, de forte conteúdo católico missionário, inclusive através do uso do inglês, seria o contraponto sugestionado, por Adichie (2011), à perspectiva de Eugene, o qual acreditava que somente mediante a renúncia da cultura local - que incluía a rejeição da língua materna - seria possível o progresso civilizatório, embora apoiasse a democracia denunciando o golpe militar em seu jornal. 
PapaNnukwu contara à umunna que Papa se oferecera para construir uma casa, comprar um carro e contratar um chofer para ele, contanto que ele se convertesse e jogasse fora o chi e o altar de sapê que havia em seu quintal. PapaNnukwu rira e respondera que só queria ver seus netos quando pudesse. Ele não ia jogar fora o seu chi; já dissera isso a Papa muitas vezes (ADICHIE, 2011, p. 69).

Eugene refere-se muitas vezes ao pai como "pagão impuro", rompe quaisquer relações com ele e impossibilita seu contato com os filhos, os quais podiam encontrar-se por poucos minutos raramente.

- O que vocês fizeram lá? Comeram alimentos oferecidos aos ídolos? Profanaram suas línguas cristãs? Fiquei paralisada; não sabia que línguas também podiam ser cristãs. - Não - afirmou Jaja. Papa estava andando na direção de Jaja. Falara a última frase toda em igbo. Achei que ia puxar as orelhas de Jaja, que ia segurá-las e sacudi-las com a mesma rapidez com que andava. (...) Mas ele disse: - Quero que terminem de comer, vão para seus quartos e rezem por perdão (ADICHIE, 2011, p. 36, grifo nosso).

O personagem PapaNnukwu pode ser vislumbrado, portanto, como representativo, do ponto de vista historiográfico, do movimento tradicionalista, centrado no enaltecimento da ideologia autóctone em inequívoca contraposição aos costumes, a língua, e a idealização de Estado aos moldes europeus. Desse modo, PapaNnukwu apresenta-se como um personagem cujo propósito é tensionar a estrutura social racista e capitalista promotora do epistemicídio.

Quanto às personagens femininas, destacam-se Beatrice e Ifeoma, mãe e tia de Kambili, respectivamente. Beatrice (Mama) é uma mulher de pequeno porte físico, com comprometimento motor, em uma das pernas, silenciosa, católica e vítima de agressão física e simbólica. Assim, "[...] [n]ão era certo permitir que uma pessoa mais velha fizesse suas tarefas, mas Mama não se incomodava; havia muita coisa com que ela não se incomodava" (ADICHIE, 2011, p. 25). Além disso, "[m]ama em geral não falava tanto de uma só vez. Ela falava da maneira como os pássaros se alimentam: aos bocadinhos" (ADICHIE, 2011, p. 26).

É esposa de Eugene e, em vista disso, desenvolve uma relação de distanciamento com a cultura Igbo, correspondente ao seu lugar de fala nesse modelo de sociedade, "[m]ama balançou a cabeça e deu um sorriso, o sorriso indulgente que se espalhava em seu rosto quando ela falava de pessoas que acreditavam em oráculos [...]" (ADICHIE, 2011, p. 27). Dito de outro modo, usa a língua materna em algumas ocasiões com os filhos, sobretudo, aquelas marcadas pela afetividade, embora evite o Igbo na interlocução com os demais, pois apesar de não negar a cultura tradicional, compreende que deve evitá-la a fim de ser uma boa esposa.

Ela sempre esperava na porta da frente no último dia de aula, para cantar músicas de agradecimento em igbo, me abraçar e abraçar Jaja e acariciar nossos boletins. Essa era a única ocasião em que Mama cantava em casa. - Orne mma, Chineke, o me mma... - cantou Mama, interrompendo-se quando a cumprimentei. - Boa tarde, Mama. - Nue, você não foi bem? Seu rosto está triste - disse ele, afastando-se para que eu passasse (ADICHIE, 2011, p. 45).

Por outro lado, sua cunhada Ifeoma, irmã de Eugene, apresenta-se como outra perspectiva de representação feminina, contrapondo-se muito a Beatrice. Decerto, "[t]ia Ifeoma era tão alta quanto Papa, com um corpo bem proporcionado. Andava rápido, como alguém que sabia exatamente aonde ia e o que ia fazer lá. E falava da mesma maneira que andava, como se quisesse dizer o máximo de palavras no menor espaço de tempo possível" (ADICHIE, 2011, p.79).

Ifeoma - segundo nome da senhora Grace Adichie, mãe da autora - é professora da Universidade de Nsukka - ofício do pai da autora - viúva que visualizava o marido como um companheiro, não como uma autoridade.

Não conhecíamos bem tia Ifeoma nem seus filhos porque ela e Papa haviam brigado por causa de PapaNnukwu. Mama nos contara. Tia Ifeoma cortara relações com Papa depois que ele proibira PapaNnukwu de entrar em sua casa, e alguns anos se passaram antes de eles voltarem a se falar (ADICHIE, 2011, p. 73).

Filha dedicada e atenciosa, possui três filhos, Amaka, Obiora e Chima, os quais educa de modo a estimular e a assegurar-lhes independência e criticidade.

Naquele instante, percebi que era isso que tia Ifeoma fazia com os meus primos, obrigando-os a ir cada vez mais alto graças à forma como falava com eles, graças ao que esperava deles. Ela fazia isso o tempo todo, acreditando que eles iam conseguir saltar. E eles saltavam. Comigo e com Jaja, era diferente. Nós não saltávamos por acreditarmos que podíamos; saltávamos porque tínhamos pânico de não conseguir (ADICHIE, 2011, p. 238).

Diferente do irmão, Ifeoma possui uma relação muito confortável com a cultura Igbo, da qual não se distancia, reforçando uma relação com o multilinguísmo nos termos apresentados por Canagarajah e Liyanage (2012). 
Na primeira vez que ouvi tia Ifeoma chamar Mama de "nwunye m", há anos, fiquei chocada, por ser uma mulher chamando a outra de "minha esposa". Quando comentei isso com Papa, ele me explicou que era o vestígio de uma tradição pagã, a idéia de que era a família toda, e não apenas o homem, que se casava. Mais tarde Mama sussurrara, apesar de estarmos sozinhas em meu quarto: - Eu sou esposa dela também, pois sou esposa de seu pai. Isso mostra que ela me aceita (ADICHIE, 2011, p.81).

Todavia, Ifeoma agencia essa relação, conforme proposto por Mbembe (2003), uma vez que nem rompe com a sua origem sociocultural, nem se nega a acessar cultura dominante, por compreender a necessidade de sua apropriação para acesso a espaços prestígio social, tal qual a universidade. Sendo assim, em conversa com o irmão,

- Para onde você quer levá-los? - perguntou Papa, que estancara ao lado da porta. - Para dar uma volta, só isso. - Um passeio? perguntou Papa, falando inglês enquanto tia Ifeoma falava igbo (ADICHIE, 2011, p. 86, grifo nosso).

O comportamento linguístico da personagem reflete o que Gumperz (1998) tratou como convenções de contextualização, as quais se referem às pistas sociolinguísticas utilizadas com intuito de denunciar práticas comunicativas ou inferir intenções discursivas do interlocutor. No que tange ao uso do inglês, é possível acionar a reflexão proposta pela feminista negra estadunidense, bell hooks (2008), acerca do verso "Esta é a língua do opressor, no entanto, preciso dela para falar com você", da poetisa Adrienne Rich. Logo,

[...] eu sei que não é a língua inglesa que me fere, mas o que os opressores fazem com ela, como eles a moldam para se tornar um território que limita e define, como eles fazem dela uma arma que pode envergonhar, humilhar, colonizar. Gloria Anzaldúa nos faz lembrar dessa dor em Border lands/La Frontera quando afirma: 'Então, se você quer mesmo me ferir, fale mal da minha língua' (HOOKS, 2008, p. 858)

hooks (2008) argumenta que o termo língua do opressor apresenta uma função desempoderadora, à proporção que esse uso escamoteia a ação dos povos colonizados, ao rasurar essa língua de colonização com as influências de suas línguas maternas, como um marcador político-cultural (GONZALEZ, 1988). Nesse sentido, para a autora, é preciso reivindicar a língua como um terreno em que povos colonizados podem refazer-se como sujeitos (UBIOWORO; ONOYOVWI, 2008).

No âmbito católico, destacam-se três perfis, o de padre Benedict, o de padre Amadi e das freiras da escola de Kambili.

Apenas as irmãs nigerianas cantavam, seus dentes brancos contrastando com a pele negra. As irmãs brancas permaneciam em silêncio de braços cruzados ou tocando de leve os rosários de vidro que pendiam de suas cinturas, certificando-se de que os lábios de todas as alunas estivessem se movendo (ADICHIE, 2011, p. 54, grifo nosso).

Enquanto os segmentos cristãos brancos promovem condições, na esfera religiosa, para o desuso do Igbo, o segmento nigeriano, o valoriza, quer na esfera religiosa, quer em outras. Logo, a tessitura textual, em que se inscreve a obra Hibisco Roxo, apresenta muitos eventos capazes de apontar para a concepção do multilinguísmo do sudeste nigeriano como um terreno de disputa e tensão sociocultural, a qual, naturalmente, se dá na língua e pela língua.

As variadas formas pelas quais os personagens se expressam na trama de Hibisco Roxo ajudam, portanto, a enriquecer o debate historiográfico que vem se desenvolvendo em África sobre os processos históricos de construção dos nacionalismos africanos a partir do período entreguerras. Oloruntimehin (2010) defende que a relação dialética entre colonizados e colonizadores, tendo como paradigma a face racista que o imperialismo europeu estimulou na organização de grupos, de movimentos sociais e de partidos políticos, de modo a buscar caminhos identitários que atendessem seus anseios, em diálogo direto ao novo contexto geopolítico que vinham se redesenhando com a polarização do mundo em plena guerra fria.

É em meio a esse complexo cenário, com múltiplas facetas, que as personagens de Hibisco Roxo se articulam, sendo a mobilização da língua Igbo versus inglês, ou em práticas translinguísticas, mais um elemento nesse imbricado movimento, pautado na luta política (CABRAL, 1978).

\section{DO EPISTEMICÍDIO AOS OSSOS AFIADOS, APESAR DA CARNE MACIA}

Campos (2015) sugere que as duas línguas, o inglês e o Igbo, não constituem uma dualidade equiparável. Pelo contrário, a opção linguística do falante revelaria o universo cultural subjacente de adesão ao sistema colonial ou de resistência ao processo opressor. Há, conforme discutido nas seções anteriores, nítido conflito por meio da 
linguagem do colonizador e do colonizado. Entretanto, no entrecruzamento das diversas falas das personagens, é possível verificar como objetivo de Adichie: registrar uso linguístico como marcas de assimilação e/ou resistência, revelando uma provável intenção em rasurar o epistemicídio, com a valorização de prática multilíngues.

À luz do debate linguístico presente no texto, é pertinente rememorar a ideia de circulação de cultura de Chartier (2015, [2007]), cujo conteúdo possibilita a visualização de que a suposta dicotomia permeada de posicionamentos políticos escamoteia, em verdade, questões que atravessam os falantes da comunidade nigeriana. Nesse sentido, ainda que, em muitos casos, haja intenção deliberada de assimilação da cultura dominante, em manifestações genuínas o Igbo é acionado, na condição de língua como elemento cultural de ordem nativa, a exemplo:

a. de felicidade: com as cantigas (Essa era a única ocasião em que Mama cantava em casa. - Orne mma, Chineke, o me mma...), com gestos de afeto (Nne - disse tia Ifeoma, dando tapinhas no meu ombro. -Seu PapaNnukwu está na varanda.) e culinária (okpa, fufu, onugbu);

b. de cumprimentos/solicitações: (- Ke kwanu? - perguntei., - Kambili, kedu?, - Me ajude aqui, biko.)

c. de fúria, como em

[c]orri para os pedaços no chão como se quisesse salvá-los, como se salvá-los fosse salvar PapaNnukwu. Atirei-me no chão, deitei sobre os pedaços de papel. - O que aconteceu com você? - perguntou Papa. - O que há de errado com você? Fiquei deitada no chão, enroscada como o feto no útero que havia numa foto do meu livro Ciência integrada para escolas do ensino médio. - Levantese! Afaste-se desse quadro! Fiquei deitada, sem reagir. - Levante-se! - repetiu Papa. Mesmo assim, não me mexi. Ele começou a me chutar. As fivelas de metal de seus chinelos doíam em minha pele como mordidas de mosquitos gigantes. Papa falou sem parar, descontroladamente, misturando igbo com inglês, carne macia com ossos afiados. Ímpios. Idolatria pagã. Fogo do inferno. O ritmo dos chutes foi aumentando, e eu pensei na música de Amaka, na música culturalmente consciente que às vezes começava com um saxofone tranquilo e, numa reviravolta, virava um canto luxurioso (ADICHIE, 2011, p. 223, grifo nosso).

O episódio em que Kambili utiliza o próprio corpo para proteger a imagem de PapaNnukwu, o qual representa a ancestralidade do povo Igbo, é um importante aspecto do processo de emancipação vivenciado por ela, tendo em vista que, apesar da carne macia, os ossos permaneceram afiados no enfrentamento ao epistemicídio. Desse modo, desde sua ida a Nsukka, a personagem, no convívio com a tia e os primos, depara-se com outras possibilidades de existência, tanto do ponto de vista da configuração familiar, regida por uma matriarca, quanto dos atravessamentos socioculturais e econômicos.

Jaja, Mama e eu falávamos mais com nosso espírito do que com nossos lábios. Até Nsukka. Nsukka começou tudo; o jardinzinho de tia Ifeoma perto da varanda de seu apartamento em Nsukka começou a romper o silêncio. A rebeldia de Jaja era como os hibiscos roxos experimentais de tia Ifeoma: rara, com o cheiro suave da liberdade, uma liberdade diferente daquela que a multidão, brandindo folhas verdes, pediu na Government Square após o golpe. Liberdade para ser, para fazer (ADICHIE, 2011, p. 22, grifo nosso).

Decerto, a ida para Nsukka e a convivência com os primos corroborou de maneira efetiva com a mudança de Kambili e de Jaja.

Amaka era uma cópia da mãe, só que adolescente e mais magra. Ela andava e falava com ainda mais rapidez e propósito do que tia Ifeoma. Só seus olhos eram diferentes; não tinham a ternura incondicional dos olhos de tia Ifeoma. Eram olhos interrogativos, que faziam muitas perguntas e não aceitavam muitas respostas. Obiora era um ano mais novo que ela e tinha a pele bem clara, olhos cor de mel cobertos por óculos de lentes grossas e uma boca cujos cantos eram virados para cima, num eterno sorriso. Chima tinha a pele escura como o fundo de uma panela de arroz queimado, e era alto para um menino de sete anos. A risada dos três era igual: gutural e gostosa, dada com entusiasmo (ADICHIE, 2011, p.87, grifo nosso).

Apesar do estranhamento inicial com a dinâmica da família da tia, Kambili sempre nutriu admiração por Ifeoma, fato que certamente contribuiu com sua "libertação", na medida em que pôde construir outra referência, a partir de outro perfil feminino, bastante distinto do de sua mãe. Sob essa ótica, a passagem abaixo destacada sugere a conscientização da personagem sobre sua negritude, da retomada da dupla consciência a que alude de Du Bois (2007) [1903] e, posteriormente, a Souza (1983), isto é, no reencontro consigo mesma em meio a um complexo jogo identitário e racializado.

Tia Ifeoma também sussurrava, mas dava para escutar direitinho tudo o que ela dizia. Seu sussurro era como ela - alto, exuberante, destemido, maior que o mundo. - Você esqueceu que Eugene se ofereceu para me comprar um carro antes até de Ifediora morrer? Mas ele queria que entrássemos para a Ordem de São João. Queria que mandássemos Amaka para um colégio de freira. Queria até que eu parasse de usar maquiagem! Eu quero um carro novo, nwunye m, quero voltar a usar meu fogão a gás, quero um freezer novo e quero dinheiro para não precisar desfazer a bainha das calças de Chima sempre que ele cresce. Mas não vou pedir que meu irmão se incline para eu puxar o saco dele e poder ganhar essas coisas (ADICHIE, 2011, p. 104, grifo nosso). 
Nesse sentido, considerando a construção da personagem Ifeoma e seu papel no processo de emancipação da sobrinha - cujo ato de defender a pintura do avô paterno culminou em uma agressão gravíssima, a qual atuou como gatilho para uma sequência de mudanças em sua composição familiar - é possível remontar à famosa frase da filósofa e feminista negra estadunidense, Ângela Davis, proferida em palestra no Salão Nobre da Reitoria da Universidade Federal da Bahia, em 25 de julho de 2017, "quando a mulher negra se movimenta, toda a estrutura se movimenta com ela", vez que está na base, dada ao cruzamento de opressões de raça e de gênero (GONZALEZ, 1983; BAIRROS, 1995; COLLINS, 2000; HOOKS, 2000, 2019; CARNEIRO, 2005, 2019; DAVIS, 2006 [1981], entre muitas outras).

Entretanto, mesmo antes desse denso processo de emancipação, fundamental para sua constituição identitária, Kambili já questionava algumas práticas estabelecidas pela estrutura social advinda da colonização e do imperialismo, como quando

Irmã Verônica chamava isso de migração anual dos igbo. Ela não entendia, dizia com seu sotaque irlandês que fazia as palavras rolarem sobre sua língua, por que tanta gente da etnia igbo construía casas enormes em suas cidades natais para passar apenas uma ou duas semanas em dezembro, enquanto tinham residências bem menores nas cidades grandes onde viviam o resto do ano. Eu sempre me perguntava por que irmã Verônica precisava entender aquilo, quando era simplesmente o nosso jeito de fazer as coisas (ADICHIE, 2011, p. 60, grifo nosso)

Logo, ainda que Kambili estivesse submetida a forte pressão emocional e social imposta pela configuração familiar, estabelecida arbitrariamente por seu pai, como via de assimilação ao modelo sociocultural de prestígio, já apresentava indícios de questionamento dessa ordem, os quais foram maturados no decorrer da trama, atingindo, finalmente, o ponto da libertação pretendido no curso de seu processo emancipatório. Tal evento pode ser considerado como tensionamento e rasura da norma epistêmica estabelecida pelo imperialismo advindo do empreendimento colonial britânico na Nigéria.

Eu não me pergunto mais se tenho o direito de amar o padre Amadi; simplesmente o amo. Não me pergunto mais se os cheques que tenho mandado aos padres missionários do Caminho Abençoado são uma forma de subornar Deus; simplesmente os mando. Não me pergunto mais se escolhi a igreja St. Andrews em Enugu como minha nova igreja porque o padre de lá é um padre missionário do Caminho Abençoado, assim como o padre Amadi; simplesmente a freqüento (ADICHIE, 2011, p.317).

À vista disso, é possível visualizar não só uma densa mudança de postura por parte de Kambili, mas também na assunção de resultado satisfatório em sua incessante busca por aquela liberdade, distinta "daquela que a multidão, brandindo folhas verdes, pediu na Government Square após o golpe. Liberdade para ser, para fazer" (ADICHIE, 2011, p. 22, grifo nosso).

\section{CONCLUSÃO}

O imperialismo inglês fruto do passado colonial fruto e as repercussões geopolíticas na Nigéria atual são, a um só tempo, o pano de fundo e o mote pelo qual as personagens interagem em Hibisco Roxo (2011), lançando luz às relações entre sujeitos colonizados e o modo pelo qual buscam caminhos de enfrentamento, resistência e acomodação de espaços. Adichie (2011) se move em discursos construídos pelo e a partir do imperialismo inglês, denunciando os efeitos produzidos pelo passado colonizado e no efeito replicador de uma lógica colonizada promovida pelos sujeitos subalternizados. Em contrapartida, as personagens, a seu modo e dentro das experiências vivenciadas, projetam formas de lidar, (sobre)viver e rasurar no/o contexto pós-colonial.

Nessa toada, se a linguagem pode ser vislumbrada como elemento de expressão cultural na qual os indivíduos ressignificam formas de convívio em sociedade (GEERTZ, 1997), as relações construídas entre as personagens merecem ser lidas e compreendidas por meio de práticas multilíngues, presentes nos usos das línguas Igbo e inglês, como marcadores identitários e também como meio de posicionamento no mundo nigeriano, fortemente permeado pelo colonialismo. Nessa rede de significados em que os sujeitos falantes se encontram (GODOY; SANTOS, 2014), são desenvolvidos estratagemas, de forma relacional ao contexto experienciado, incluindo, nesse itinerário, a língua.

De todo modo, a trama alinhavada por Adichie não só problematiza as influências decorrentes do percurso histórico atravessado na Nigéria, como também ajuda a (re)pensar os deslocamentos necessários na construção de concepções teóricas pautadas na ideia da diversidade, dentro de um pluralismo efetivamente democrático e inclusivo.

Nesse viés, para além da importância do livro como ferramenta da pluralização de formas de narrar o passado e da ampliação de horizontes em torno da representação literária, as propostas de Adichie acenam para um maior debate 
sobre a linguagem, em face ao multilinguísmo e o epistemicídio, em um contexto ocidentalizado, do qual integramos. No limite, o jogo em disputa na visão dicotômica entre as línguas materna e colonizadora servem como um convite à oxigenação de aportes teóricos, mediante a revisitação dos pressupostos epistêmicos da própria Linguística.

\section{REFERÊNCIAS}

ADICHIE, Chimamanda Nzogi. (2011). Hibisco roxo. Tradução Julia Romeu. São Paulo: Companhia das Letras.

ALMEIDA, Silvio. (2018). O que é racismo estrutural? Coleção Feminismos Plurais. Belo Horizonte: Editora Letramento.

BAIRROS, Luíza. (1995). Nossos feminismos revisitados. In: RIBEIRO, Matilde (Org.). Revista Estudos Feministas, Dossiê Mulheres Negras, Florianópolis, v. 3, n. 3, p. 458-463.

BARREIROS, Patrício Nunes. (2017). Por uma abordagem da História Cultural das práticas de escrita na edição de textos. ALEA, Rio de Janeiro, vol. 19/2, maio-ago., p. 389-414.

BASSANI, Indaiá de Santana. (2015). Disciplina Fundamentos Linguísticos: bilinguísmo e multilinguísmo. São Paulo: Edusp.

BOAHEN, Albert Adu. (2010).A África diante do desafio colonial. In: BOAHEN, A. Adu (ed.). História Geral da África - A África sob dominação colonial, 1880-1935. 2.ed. rev. Brasília: UNESCO, cap. I, p.1.22.

BORGES, Rosa. (2020). Experiências e descentramentos epistemológicos na prática filológica. In: SOUZA, Risonete Batista de. [et al.]. Filologia em diálogo: descentramentos culturais e epistemológicos. Salvador: Memória \& arte, p. 15-47.

CABRAL, Amílcar. (1978). Unidade e Luta I. A Arma da Teoria. Textos coordenados por Mário Pinto de Andrade, Lisboa: Seara Nova.

CAMPOS, Juliana Sant'Ana. (2015). As manipulações das etnicidades como forma de controle, exploração e alienação em Hibisco Roxo de Chimamanda Ngozi Adichie. Revista Crioula USP, n. 16.

CANAGARAJAH, Suresh.; LIYANAGE, Indica. (2012). Lessons from pre-colonial multilingualism. In: MARTIN-JONES, A.; BLACKLEDGE, A.; CREESE, A. (Eds.). The Routledge bandbook of multilingualism. London: Routledge, p. 49-65.

CARNEIRO, Aparecida Sueli. (2005). A construção do outro como não-ser como fundamento do ser. Tese (Doutorado em Educação) Faculdade de Educação, Universidade de São Paulo, São Paulo.

CARNEIRO, Aparecida Sueli. (2019). Escritos de uma vida. São Paulo: Pólen Livros.

CHARTIER, Roger. (2015 [2007]). A bistória ou a leitura do tempo. $2^{\mathrm{a}}$ edição. Belo Horizonte: Autêntica.

COLLINS, Patrícia Hill. (2000). Black Feminist Thought: Knowledge, Conciousness and the Politics of Empowerment. Nova York: Routledge.

DAVIS, Angela. (2016 [1981]). Mulberes, Raça e Classe. Tradução de Heci Regina Candiani. São Paulo: Boitempo.

DU BOIS, William E. B. (2007 [1903]). The souls of black folk. Oxford: Oxford University Press.

ERNEST-SAMUEL, Gloria Chimenziem. (2019). Língua e Literatura Igbo no Discurso em Sala de Aula: um experimento pedagógico. Revista Brasileira de Estudos da Presença, v. 9, n. 1, p. 1-22.

FANON, Frantz. (2008). Peles negras, máscaras brancas. Tradução de Renato da Silveira. Salvador: EDUFBA.

FOUCAULT, Michel. (1979). Microfísica do poder. Rio de Janeiro, Graal.

GALLIE, Walter B. (2016). Narrativa e Compreensão histórica. In: MALERBA, Jurandir (org.). História e narrativa: a ciência e a arte da escrita histórica. Petrópolis: Vozes. 
GEERTZ, Clifford. (2001 [1989]). Nova Luz sobre a Antropologia. Rio de Janeiro: Jorge Zahar.

GODOY, Elenilton Vieira; SANTOS, Vinício de Macedo. (2014). Um olhar sobre a cultura. Educação em Revista, Belo Horizonte, v. 30, n. 3, p. $15-41$.

GONÇALVES, Ana. Maria. (2006). Um defeito de cor. Rio de Janeiro: Record.

GONZALEZ, Lélia. (1983). Racismo e sexismo na cultura brasileira. Revista Ciências Sociais Hoje, ANPOCS, p. 223 -244.

GONZALEZ, Lélia. (1988). A categoria político-cultural de amefricanidade. Tempo Brasileiro, Rio de Janeiro, n. 92-93, p. 69-82.

GROSJEAN, François. (1982). Life with two languages: an introduction to bilingualism. Cambridge: Harvard University Press.

GUMPERZ, John. (1988). Convenções de contextualização. In: GUMPERZ, John. Sociolinguística interacional: antropologia, linguística e sociologia em análise do discurso. Porto Alegre: Editora AGE, p. 98-119.

GINZBURG, Carlo. (2006). O extermínio dos judeus e o princípio da realidade. Enredo e verdade na escrita da história. In: MALERBA, Jurandir (org.). A História Escrita: teoria e história da historiografia. São Paulo, Contexto, p. 211-230.

HALL, Stuart. (1992). A identidade em questão. In: HALL, S. A identidade cultural na pós modernidade. Rio de Janeiro: DP\&A editora, p. 7-13.

HALL, Stuart. (2003). Da diáspora: identidade e mediações culturais. In: SOVIK, Liv (Org.). Tradução de Adelaine Resende [et al.]. Belo Horizonte: Editora UFMG; Brasília: Representação da UNESCO no Brasil.

HOOKS, bell. (2000). Feminist is for Everybody: Passionate Politics. Pluto Express.

HOOKS, bell. (2008). Linguagem: ensinar novas paisagens/novas linguagens. In: Estudos Feministas, v.16, n. 3.

HOOKS, bell. (2019). Olhares negros: raça e representação. Tradução de Stephanie Borges. São Paulo: Editora Elefante.

LE GOFF, Jacques. (2003 [1988]). História e memória. Tradução Irene Ferreira, Bernardo Leitão e Suzana Ferreira Borges. 5. ed. Campinas: Editora da UNICAMP.

LEMOS, Amélia Francisco Felipi da C. (2018). Língua e cultura em contexto multilingue: um olhar sobre o sistema educativo em Moçambique. Educar em Revista, Curitiba, v. 34, n. 69, p. 17-32.

MCKENZIE, Donald Francis. (2018 [1986]). Bibliografia e a Sociologia dos textos. Tradução: Fernanda Veríssimo. São Paulo: Editora da universidade de São Paulo.

MBEMBE, Achille. (2003). África Insubmissa: cristianismo, poder e Estado na sociedade pós-colonial. Editora Edições Padago: Odivelas; Edições Mulemba: Luanda.

MBEMBE, Achille. (2014). A crítica da razão negra. Lisboa: Antígona.

MBEMBE, Achille. (2015). Decolonizing Knowledge and the Question of the Archive. Ms. Disponível em <https://wiser.wits.ac.za/ system/files/Achille\%20Mbembe\%20-\%20Decolonizing\%20Knowledge\%20and\%20the\%20Question\%20of\%20the\%20 Archive.pdf > Acesso em 21 de outubro.

MBEMBE, Achille. (2018). Necropolítica. São Paulo: N-1 edições.

MOITA LOPES, Luiz Paulo. (Org.). (2006). Por uma Linguística Aplicada INdisciplinar. Parábola: São Paulo.

MOITA LOPES, Luiz Paulo. (2009). Da aplicação da Linguística à Linguística Aplicada. In: PEREIRA, Regina Celi; ROCA, Pilar. Linguística Aplicada: um caminho com diferentes acessos. São Paulo: Contextos.

MUFWENE, Salikoko S. (2016). Ecologia da língua: algumas perspectivas evolutivas. Ecolinguística: Revista Brasileira de Ecologia e Linguagem, v. 02, n. 01, p. 21-38. 
MÜLLER, Fernanda de Oliveira. (2016). Traços de etnicidade na tradução de Purple Hibiscus. Bela Infiéis, v. 5, n. 2, p. $09-18$.

MUNIZ, Kassandra da Silva. (2009). Linguagem e identificação: uma contribuição para o debate sobre ações afirmativas para negros no Brasil. Tese (Doutorado em Linguística), Instituto de Estudos da Linguagem, Universidade do Estado de Campinas, Campinas.

ODINYE; Israel; ODINYE, Ify. (2010). Preventing the Extinction of Igbo Language. OGIRISI: a New Journal of African Studies: Editorial Policies, Nigeria, v. 7, p. 85-93.

OLORUNTIMEHIN, B. Olantunji. A política e o nacionalismo africanos, 1919-1935. (2010). In: BOAHEN, A. Adu (ed.). História Geral da África - A África sob dominação colonial, 1880-1935. 2.ed. rev. Brasília: UNESCO, cap.VII, p.657-674.

RIBEIRO, Djamila. (2017). O que élugar de fala? Coleção Feminismos Plurais. Belo Horizonte: Editora Letramento.

SOUSA SANTOS, Boaventura. (1995). Pela Mão de Alice. São Paulo: Cortez Editora.

SOUZA, Neusa Santos. (1983). Tornar-se negro: vicissitudes da identidade do negro brasileiro em ascensão social. Rio de Janeiro: Edições Graal.

UBIOWORO, Eyo; ONOYOVWI, Doe. (2008). Towards re-tooling oral literature for the teaching of Nigerian Languages. Journal of Nigerian Languages and Culture, Nigeria, v. 10, n. 2, p. 135-146.

TEOTONIO, Rafaella Cristina Alves. (2013). Por uma modernidade própria: o transcultural nas obras Hibisco Roxo, de Chimamanda Ngozi Adichie e o Sétimo juramento, de Paula Chiziane. Dissertação de Mestrado. Programa de Pós-Graduação em Literatura e Interculturalidade da Universidade Estadual da Paraíba.

VISSENTINI, Paulo Fagundes. (2011). Livro na rua: Nigéria. Theasaurus Editora: Brasília.

Recebido: $27 / 10 / 2020$

Aceito: $12 / 3 / 2021$

Publicado: 16/6/2021 